\title{
Gambaran Kadar Gula Darah pada Mahasiswa Fakultas Kedokteran Universitas Andalas yang Memiliki Berat Badan Berlebih dan Obesitas
}

\author{
Putri Auliya ${ }^{1}$, Fadil Oenzil ${ }^{2}$, Zelly Dia Rofinda ${ }^{3}$
}

\begin{abstract}
Abstrak
Obesitas dan berat badan berlebih merupakan faktor predisposisi terhadap resistensi insulin yang dapat menyebabkan peningkatan kadar gula darah sehingga terjadi diabetes mellitus tipe 2. Tujuan penelitian ini adalah untuk mengetahui gambaran kadar gula darah pada dewasa muda yang diwakili oleh mahasiswa Fakultas Kedokteran Universitas Andalas yang memiliki berat badan berlebih dan obesitas. Penelitian ini merupakan penelitian deskriptif dengan rancangan cross sectional. Penelitian ini dilakukan di Fakultas Kedokteran Universitas Andalas Padang. Sampel penelitian diambil dari total populasi yakni sebanyak 25 orang yang diperiksa kadar gula darah puasa, TTGO, IMT dan aktivitas fisik. Hasil penelitian ini menggambarkan telah terjadi peningkatan kadar gula darah puasa yakni GDPT sebanyak $32 \%$ dan diabetes sebanyak $28 \%$. Pada gula darah TTGO terjadi peningkatan sebanyak $16 \%$ yakni TGT. Peningkatan kadar gula darah ini sangat berhubungan dengan aktivitas fisik, yakni $16 \%$ responden dengan aktivitas fisik ringan didapatkan interpretasi diabetes pada gula darah puasa sedangkan aktivitas berat hanya $8 \%$ dan sedang 4\%. Begitu pula dengan kadar gula TTGO yakni sebanyak $8 \%$ mengalami TGT pada responden dengan aktivitas fisik ringan. Kesimpulannya sebagian besar sampel yang memiliki berat badan berlebih dan obesitas mengalami peningkatan kadar gula darah pada interpretasi TGT, GDPT dan Diabetes.
\end{abstract}

Kata kunci: kadar gula darah, obesitas, berat badan berlebih, TTGO, TGT, diabetes

\section{Abstract}

Obesity and overweight is a predisposing factor insulin resistance which causes an increase in blood sugar levels in type 2 diabetes mellitus. The objective of this study was to reveal the blood sugar levels of medical students in andalas university whom are overweight and obese. This was a descriptive study with a cross sectional design. This study was conducted in Medicine Faculty of Andalas University Padang. Samples from this study is the total sampling population of 25 people. The variables were fasting blood sugar, glucose tolerance, BMI and Physical Activity. This study illustrate the increasing in fasting blood sugar level as prediabetes $32 \%$ and diabetes $28 \%$. In the oral glucose tolerance, TGT was identified to cause an of blood sugar increased by $16 \%$. Increased blood sugar levels was highly associated with physical activity, which is $16 \%$ of respondents with mild physical activity displayed an interpretation of diabetes from the fasting blood sugar, in strenuous activities $8 \%$ and moderate activity $4 \%$. Similarly, the glucose tolerance as much as $8 \%$ had IGT in respondents with mild physical activity. The conclution of this study is the subjects with overweight and obesity have elevated level of blood sugar in interpretation of IGT, IFG, and diabetes.

Keywords: blood glucose levels, obesity, overweight, IGT, IFG, diabetes

Affiliasi penulis: 1. Prodi Profesi Dokter FK UNAND (Fakultas Kedokteran Universitas Andalas Padang), 2. Bagian Biokimia FK UNAND, 3. Bagian Patologi Klinik FK UNAND/RSUP Dr. M. Djamil Padang
Korespondensi: Putri Auliya, Email: putriauliya@icloud.com Telp: 081266016456 


\section{PENDAHULUAN}

Glukosa merupakan salah satu bentuk hasil metabolisme karbohidrat yang berfungsi sebagai sumber energi utama yang dikontrol oleh insulin. Kelebihan glukosa diubah menjadi glikogen yang akan disimpan di dalam hati dan otot untuk cadangan jika diperlukan. Peningkatan kadar glukosa darah terjadi pada penderita Toleransi Glukosa Terganggu (TGT), Gula Darah Puasa Terganggu (GDPT) dan Diabetes Mellitus (DM). ${ }^{1,2}$

Obesitas dan berat badan berlebih (overweight) merupakan salah satu masalah yang mulai menjadi sorotan dunia termasuk di Indonesia. Pada populasi dunia, $25 \%$ penduduk mengalami obesitas, yang kebanyakan (59\%) dengan onset umur pertengahan dewasa. Sedangkan prevalensi nasional Gizi Lebih di Indonesia pada penduduk umur $\geq 15$ tahun adalah $10,3 \% .^{3,4}$

Obesitas adalah suatu kondisi dengan penyebab ganda yang menyebabkan IMT (Indeks Masa Tubuh) $\geq 30 \mathrm{~kg} / \mathrm{m}^{2}$ sedangkan berat badan berlebih (overweight) adalah keadaan dengan IMT > $25 \mathrm{~kg} / \mathrm{m}^{2}$ dan $<30 \mathrm{~kg} / \mathrm{m}^{2}$. Berat badan ditentukan oleh interaksi antara genetik, faktor lingkungan, energi masuk, energi keluar dan psikososial yang bertindak melalui mediator fisiologis antara asupan energi dan pengeluaran. Meskipun perbedaan genetik penting, kenaikan prevalensi obesitas lebih banyak dijelaskan oleh perubahan perilaku dan lingkungan karena kemajuan teknologi. Energi masuk dan energi keluar yang tidak seimbang merupakan salah satu penyebab dari pola makan. Pola makan seseorang dikendalikan oleh hipotalamus. Hipotalamus memiliki 2 bagian yang mempengaruhi penyerapan makanan yakni hipotalamus lateral dan hipotalamus ventromedial. Bila terjadi kerusakan pada hipotalamus ventromedial maka nafsu makan seseorang akan bertambah. Selain itu lesi ini menyebabkan kelebihan produksi insulin yang selanjutnya meningkatkan penyimpanan lemak. 3,5

Berat badan berlebih dan obesitas merupakan faktor predisposisi terhadap banyak penyakit., yakni resistensi insulin yang menyebabkan peningkatan kadar gula darah sehingga dapat jatuh pada diabetes mellitus tipe 2, Penyakit Jantung Koroner (PJK) dan penyakit lainnya, sehingga obesitas menjadi sorotan dunia. ${ }^{6}$

Asupan kalori yang melebihi pengeluaran energi, akan meningkatkan hasil mitokondria NADH (mNADH) dan Reactive Oxygen Species (ROS). Pembentukan ROS dapat dikurangi dengan melakukan pencegahan penumpukan mNADH dengan menghambat rangsangan insulin dan mencegah masuknya substrat ke dalam mitokondria, sehingga resistensi insulin dapat dianggap sebagai mekanisme kompensasi yang melindungi sel-sel terhadap serapan asam lemak dan kerusakan oksidatif. Resistensi insulin ini belum menyebabkan diabetes klinis, dimana sel $\beta$ pankreas masih dapat mengompensasi, sehingga terjadi hiperinsulinemia dengan kadar glukosa darah masih normal atau sedikit meningkat. Bila sudah terjadi kelelahan sel $\beta$ pankreas, baru timbul DM klinis yang ditandai dengan kadar gula darah yang meningkat. Dalimunthe pada tahun 2008, dalam Justitia (2012) menyebutkan 70\% kejadian Glukosa Darah Puasa Terganggu (GDPT) akan menjadi penderita DM dalam jangka 6-10 tahun kemudian. ${ }^{7,8}$

Tingginya hubungan antara berat badan dengan kejadian peningkatan kadar gula darah, maka perlu dlakukan penelitian untuk mengetahui apakah sudah terjadi peningkatan kadar gula darah pada dewasa muda yang overweight dan obesitas yang nantinya berhubungan dengan awal mula terjadinya resistensi insulin. Pemilihan mahasiswa Fakultas Kedokteran Universitas Andalas sebagai subjek penelitian dengan alasan kurangnya aktivitas fisik mahasiswa yang menjadi salah satu faktor risiko peningkatan kadar gula darah.

\section{METODE}

Jenis penelitian yang dilakukan adalah deskriptif observasional dengan desain cross sectional study berdasarkan jumlah mahasiswa yang obesitas dan overweight untuk mengetahui kadar gula darah.

Penelitian dilakukan dari November 2012 Februari 2013. Tempat penelitian adalah kampus Fakultas Kedokteran Universitas Andalas Jati.

Populasi penelitian adalah mahasiswa yang memiliki Indeks Massa Tubuh diatas 23. Sampel 
penelitian adalah subjek yang diambil dari populasi studi yang memenuhi kriteria inklusi dan eklusi. Jumlah populasi adalah 25 orang. Pengambilan sampel yang digunakan adalah dengan metode total sampling sehingga jumlah populasi sama dengan jumlah sampel yakni 25 orang.

Penelitian ini dilakukan dengan mengambil data yang terdiri dari data antopometri subjek, gula darah puasa, dan gula darah 2 jam post prandial.

HASIL

Tabel 1. Karakteristik responden

\begin{tabular}{|c|c|c|c|c|c|}
\hline \multirow{2}{*}{\multicolumn{2}{|c|}{ Karakteristik }} & \multicolumn{2}{|c|}{ Overweight } & \multicolumn{2}{|c|}{ Obesitas } \\
\hline & & $n$ & $\%$ & $\mathbf{N}$ & $\%$ \\
\hline \multicolumn{6}{|c|}{ Jenis Kelamin } \\
\hline- & Laki-laki & 5 & 20 & 10 & 40 \\
\hline- & Perempuan & 2 & 8 & 8 & 32 \\
\hline Jumlah & & 7 & 28 & 18 & 72 \\
\hline \multicolumn{6}{|c|}{ Risiko Obesitas } \\
\hline- & Memiliki risiko & 5 & 20 & 18 & 72 \\
\hline- & $\begin{array}{l}\text { Tidak memiliki } \\
\text { risiko }\end{array}$ & 2 & 8 & 0 & 0 \\
\hline Jumlah & & 7 & 28 & 18 & 72 \\
\hline \multicolumn{6}{|c|}{ Risiko Diabetes } \\
\hline- & Memiliki risiko & 4 & 16 & 11 & 44 \\
\hline- & $\begin{array}{l}\text { Tidak memiliki } \\
\text { risiko }\end{array}$ & 3 & 12 & 7 & 28 \\
\hline Jumlah & & 7 & 28 & 18 & 72 \\
\hline \multicolumn{6}{|l|}{ Umur } \\
\hline- & 19 tahun & 3 & 12 & 3 & 12 \\
\hline- & 20 tahun & 3 & 12 & 4 & 16 \\
\hline- & 21 tahun & - & - & 9 & 36 \\
\hline- & 22 tahun & 1 & 4 & 2 & 8 \\
\hline Jumlah & & 7 & 28 & 18 & 72 \\
\hline
\end{tabular}

Berdasarkan jenis kelamin, responden perempuan lebih banyak daripada laki-laki. Risiko responden overweight terhadap obesitas, jumlah responden yang memiliki risiko ialah sebanyak 20\% (5 orang), sedangkan yang tidak memiliki risiko yakni $8 \%$ (2 orang). Pada responden obesitas jika dilihat dari risiko obesitasnya, maka yang berisiko adalah sebanyak $72 \%$ (18 orang), sedangkan yang tidak memiliki risiko tidak ada. Ditinjau dari risiko terhadap diabetes, pada responden overweight yang memiliki risiko adalah sebanyak 16\% (4 orang) dan yang tidak memiliki risiko sebanyak $12 \%$ (3 orang), sedangkan pada responden obesitas yang memiliki risiko diabetes adalah sebanyak 44\% (11 orang) dan yang tidak memiliki risiko sebanyak $28 \%$ (7 orang).

Tabel 2. Kadar gula darah puasa

\begin{tabular}{lcccc}
\hline Kelompok & $\mathbf{n}$ & Rerata & Min & Maks \\
\hline $\begin{array}{l}\text { Normal } \\
\text { Kadar Gula }\end{array}$ & 10 & 84,0 & 78 & 89 \\
$\quad$ Darah & & & & \\
GDPT & 8 & & & \\
$\quad$ Kadar Gula & & 95,75 & 91 & 98 \\
$\quad$ Darah & & & & \\
$\begin{array}{l}\text { Diabetes } \\
\text { Kadar Gula }\end{array}$ & 7 & 106,43 & 102 & 115 \\
$\quad$ Darah & & & & \\
\hline
\end{tabular}

Rerata kadar gula darah pada kelompok normal adalah $84 \mathrm{mg} / \mathrm{dL}$ dengan kadar gula darah terendah $78 \mathrm{mg} / \mathrm{dL}$ dan tertinggi $89 \mathrm{mg} / \mathrm{dL}$. Pada kelompok GDPT (Glukosa Darah Puasa Terganggu), hasil pengukuran kadar gula darah menunjukkan rerata 95,75 mg/dL dengan kadar gula darah terendah 91 $\mathrm{mg} / \mathrm{dL}$ dan tertinggi $98 \mathrm{mg} / \mathrm{dL}$. Sedangkan pada kelompok diabetes didapatkan kadar gula darah rerata $106,43 \mathrm{mg} / \mathrm{dL}$ dengan nilai kadar gula darah terendah $102 \mathrm{mg} / \mathrm{dL}$ dan tertinggi $115 \mathrm{mg} / \mathrm{dL}$.

Tabel 3. Kadar gula darah 2 jam post prandial

\begin{tabular}{|c|c|c|c|c|}
\hline Kelompok & $\mathbf{n}$ & Rerata & Min & Maks \\
\hline Normal & 21 & & & \\
\hline Kadar Gula & & 111,4 & 85 & 139 \\
\hline \multicolumn{5}{|l|}{ Darah } \\
\hline TGT & 4 & & & \\
\hline Kadar Gula & & 148,5 & 145 & 155 \\
\hline \multicolumn{5}{|l|}{ Darah } \\
\hline Diabetes & 0 & & & \\
\hline Kadar Gula & & - & - & - \\
\hline Darah & & & & \\
\hline
\end{tabular}

Pada Tabel 3 dapat dilihat bahwa rerata kadar gula darah pada kelompok normal adalah $111,47 \mathrm{mg} / \mathrm{dL}$ dengan kadar gula darah terendah 85 mg/dL dan tertinggi $139 \mathrm{mg} / \mathrm{dL}$. Pada kelompok TGT (Toleransi Glukosa Terganggu), hasil pengukuran kadar gula darah menunjukkan rata-rata $148,5 \mathrm{mg} / \mathrm{dL}$ dengan kadar gula darah terendah $145 \mathrm{mg} / \mathrm{dL}$ dan 
tertinggi $155 \mathrm{mg} / \mathrm{dL}$. Pada diabetes, tidak didapatkan satupun responden dengan kadar gula darah diatas $200 \mathrm{mg} / \mathrm{dL}$.

Tabel 4. Distribusi gula darah puasa tehadap IMT

\begin{tabular}{lcccc}
\hline \multirow{2}{*}{ Gula Darah } & \multicolumn{2}{c}{ Overweight } & \multicolumn{2}{c}{ Obesitas } \\
\cline { 2 - 5 } & $\mathbf{n}$ & $\%$ & $\mathbf{n}$ & $\%$ \\
\hline Normal & 2 & 8 & 8 & 32 \\
GDPT & 3 & 12 & 5 & 20 \\
Diabetes & 2 & 8 & 5 & 20 \\
\hline Jumlah & 7 & 28 & 18 & 72
\end{tabular}

Berdasarkan Tabel 4 dapat dilihat bahwa sudah terjadi peningkatan kadar gula darah puasa pada kelompok responden overweight sebanyak $20 \%$ yang terdiri dari GDPT $12 \%$ dan diabetes $8 \%$. Demikian pula pada kelompok responden obesitas telah terjadi peningkatan kadar gula darah sebanyak $40 \%$ yang terdiri dari GDPT 20\% dan diabetes 20\%. Tetapi seperti yang terlihat pada Tabel 4 peningkatan kadar gula darah pada responden yang termasuk kelompok diabetes tidak begitu tinggi, melainkan peningkatan sedikit dari batas normal.

Tabel 5. Distribusi gula darah 2 jam post prandial tehadap IMT

\begin{tabular}{lcccc}
\hline \multirow{2}{*}{ Gula Darah } & \multicolumn{2}{c}{ Overweight } & \multicolumn{2}{c}{ Obesitas } \\
\cline { 2 - 5 } & $\mathbf{n}$ & $\%$ & $\mathbf{n}$ & $\%$ \\
\hline Normal & 7 & 28 & 14 & 62 \\
TGT & - & - & 4 & 20 \\
Diabetes & - & - & - & - \\
\hline Jumlah & 7 & 28 & 18 & 72 \\
\hline
\end{tabular}

Pada Tabel 5 dapat dilihat bahwa tidak terjadi peningkatan kadar gula darah 2 jam post prandial pada kelompok responden overweight. Sedangkan pada kelompok responden obesitas telah terjadi peningkatan kadar gula darah sebanyak $20 \%$ TGT dan tidak satupun dari kelompok obesitas maupun overweight yang dikatakan diabetes dalam pemeriksaan gula darah 2 jam post prandial.

Tabel 6 memperlihatkan peningkatan kadar gula darah puasa pada kelompok diabetes terjadi paling banyak pada responden yang memiliki aktivitas fisik ringan yakni sebanyak $16 \%$ diikuti pada responden yang memiliki aktivitas fisik berat yakni $8 \%$ dan $4 \%$ pada responden dengan aktivitas fisik sedang.
Tabel 6. Distribusi aktivitas fisik

\begin{tabular}{lcccccc}
\hline \multirow{2}{*}{$\begin{array}{c}\text { Gula } \\
\text { Darah }\end{array}$} & \multicolumn{2}{c}{$\begin{array}{c}\text { Aktivitas } \\
\text { Ringan }\end{array}$} & \multicolumn{2}{c}{$\begin{array}{c}\text { Aktivitas } \\
\text { Sedang }\end{array}$} & \multicolumn{2}{c}{$\begin{array}{c}\text { Aktivitas } \\
\text { Berat }\end{array}$} \\
\cline { 2 - 7 } & $\mathbf{n}$ & $\%$ & $\mathbf{n}$ & $\%$ & $\mathbf{n}$ & $\%$ \\
\hline Normal & 7 & 28 & - & - & 3 & 12 \\
GDPT & 1 & 4 & 3 & 20 & 4 & 16 \\
Diabetes & 4 & 16 & 1 & - & 2 & 8 \\
\hline Jumlah & 12 & $48 \%$ & 4 & $16 \%$ & 9 & $36 \%$ \\
\hline
\end{tabular}

Peningkatan kadar gula darah puasa pada kelompok GDPT, terjadi peningkatan terbanyak pada responden yang memiliki aktivitas fisik berat (16\%) diikuti oleh responden dengan aktivitas fisik sedang (12\%) dan ringan (4\%).

Tabel 7. Distribusi kadar gula darah 2 jam post prandial dan aktivitas fisik

\begin{tabular}{lcccccc}
\hline \multirow{2}{*}{$\begin{array}{c}\text { Gula } \\
\text { Darah }\end{array}$} & \multicolumn{2}{c}{$\begin{array}{c}\text { Aktivitas } \\
\text { Ringan }\end{array}$} & \multicolumn{2}{c}{$\begin{array}{c}\text { Aktivitas } \\
\text { Sedang }\end{array}$} & \multicolumn{2}{c}{$\begin{array}{c}\text { Aktivitas } \\
\text { Berat }\end{array}$} \\
\cline { 2 - 7 } & $\mathbf{n}$ & $\%$ & $\mathbf{n}$ & $\%$ & $\mathbf{n}$ & $\%$ \\
\hline Normal & 10 & 40 & 3 & 12 & 8 & 32 \\
TGT & 2 & 8 & 1 & 4 & 1 & 4 \\
Diabetes & - & - & - & - & - & - \\
\hline Jumlah & 12 & $48 \%$ & 4 & $16 \%$ & 9 & $36 \%$ \\
\hline
\end{tabular}

Berdasarkan Tabel 7 dapat dilihat bahwa peningkatan kadar gula darah 2 jam post prandial pada kelompok TGT terjadi paling banyak pada responden yang memiliki aktivitas fisik ringan yakni sebanyak $8 \%$ (2 orang) diikuti pada responden yang memiliki aktivitas fisik sedang dan berat yakni masingmasing 4\% (1 orang).

\section{PEMBAHASAN}

Berdasarkan hasil penelitian yang telah dilakukan ini, responden yang memiliki berat badan berlebih atau obesitas memiliki rerata memiliki risiko terhadap peningkatan berat badan yaitu sebanyak 23 orang (92\%) dari total 25 responden. Berdasarkan literatur Afiani tahun 2010, risiko peningkatan berat badan terjadi lebih banyak pada orang yang memiliki riwayat keturunan obesitas. $^{9}$

Kebanyakan responden memiliki aktivitas fisik ringan yakni 48\% (12 orang) diikuti dengan aktivitas fisik berat sebanyak 36\% (9 orang) dan ringan sebanyak $16 \%$ (4 orang). Hasil ini sesuai dengan literatur dari Afini tahun 2010 yang menyatakan bahwa 
peningkatan berat badan terjadi akibat akumulasi jaringan lemak yang berlebih, dimana akumulasi ini terjadi akibat enargi yang masuk lebih banyak dari energi keluar. Mahasiswa sebagai seorang dewasa muda, maka makanan tidak lagi berfungsi untuk pertumbuhan dan hanya untuk mempertahankan keadaan gizi yang sudah ada atau meningkatkan keadaan gizi yang sebelumnya kurang. ${ }^{9}$

Pemeriksaan gula darah menggunakan alat glukocheck dengan quality control with in ren setiap 5 sampel. Nilai CV (Coefficient Variation) untuk kontrol kadar gula rendah adalah 3,5\% dan kontrol kadar gula tinggi $2,8 \%$ yang menunjukkan alat terkontrol dengan baik.

Berdasarkan pemeriksaan kadar gula darah puasa, telah terjadi peningkatan kadar gula darah puasa yang digolongkan sebagai GDPT (32\%) dan Diabetes (28\%). Hasil ini sesuai dengan penelitian sebelumnya yang meneliti perbedaan antara gula darah pria dewasa muda obesitas dengan pria dewasa muda normal dimana pada hasil penelitian tersebut juga didapatkan peningkatan kadar gula darah puasa pada pria dewasa yang obesitas. Hasil pemeriksaan ini juga mendukung teori bahwa kegemukan dan distribusi lemak dapat mengubah metabolisme glukosa dan terjadinya insulin resisten.

Bersamaan dengan hasil pemeriksaan gula darah puasa, hasil pemeriksaan gula darah 2 jam post prandial juga memperlihatkan peningkatan sampai kelompok TGT sebanyak 16\% (4 orang). Hasil ini juga mendukung teori bahwa kegemukan dapat menyebabkan terjadinya resistensi insulin yang digambarkan oleh peningkatan kadar gula darah. Hasil pemeriksaan gula darah 2 jam post prandial ini juga sama dengan hasil penelitian Pradana Soewondo dkk pada tahun 2006 yakni terjadi peningkatan kadar gula darah pada orang yang memiliki IMT lebih pada pemeriksaan TTGO. ${ }^{10}$

Seseorang dengan aktivitas fisik ringan akan berisiko untuk peningkatan kadar gula darah dibandingkan orang yang memiliki aktivitas fisik berat. Hal ini terlihat dari hasil Riset Kesehatan Dasar tahun 2007 yang menyatakan bahwa salah satu faktor risiko peningkatan kadar gula darah adalah kurangnya aktivitas fisik. Aktivitas fisik dapat menyebabkan peningkatan kadar gula darah melalui 2 cara, yakni dengan kurangnya aktivitas fisik maka penumpukan jaringan lemak akan semakin tinggi yang dapat menyebabkan resistensi insulin dan kurangnya aktivitas fisik juga dapat menyebabkan pengurangan kemampuan jaringan menerima insulin. Teori-teori di atas juga digambarkan dari hasil penelitian bahwa peningkatan kadar gula darah puasa dan 2 jam post prandial lebih banyak terjadi pada responden yang memiliki aktivitas fisik ringan. ${ }^{4}$

\section{KESIMPULAN}

Peningkatan kadar gula darah lebih tinggi terjadi pada mahasiswa yang memiliki aktivitas fisik ringan dibandingkan mahasiswa yang memiliki aktivitas fisik sedang dan berat.

\section{UCAPAN TERIMAKASIH}

Terimakasih kepada kepada responden yang telah bersedia meluangkan waktu demi berhasilnya penelitian ini dan staf FK UNAND yang senantiasa mendukung dalam menjalani penelitian ini.

\section{DAFTAR PUSTAKA}

1. Dorland WA. Newman. Kamus Kedokteran Dorland. Edisi ke-29. Jakarta: EGC: 2000.

2. Perkumpulan Endokrinologi Indonesia. Konsensus dan pengelolaan diabetes mellitus tipe $2 \mathrm{di}$ Indonesia. 2010.

3. WHO. Obesity and overweight. (diunduh 8 Mei 2012). Tersedia dari: URL: HYPERLINK http://www.who.int/mediacentre/factsheet/fs311/en/

4. Riset Kesehatan Dasar. Laporan nasional 2007. Badan Penelitian dan Pengembangan Kesehatan Republik Indonesia; 2008.

5. Guyton AC, Hall JE. Buku Ajar Fisiologi Kedokteran (terjemahan). Edisi ke-9. Philadelphia: WB Sounders Company; 1997.

6. Kopelman, Peter G. Obesity as a Medical problem, Nature. Macmillan Magazine. Edisi 6 April 2000.

7. Ceriello $A$, Enrico $M$. Is oxydative stress the athogenic mechanism underlying insulin resistance, diabetes, and cardiovascular disease? The common soil hypothesis revisited. Journal of American Heart Association Arterioscler Thromb Vasc Biol. 2004;24:816-23. 
8. Justitia. Hubungan obesitas dan peningkatan kadar gula darah pada guru-guru SMP N 3 Medan (skripsi). Medan:Fakultas Kedokteran Universitas Sumatera Utara; 2012.

9. Afiani D. Gambaran Pengetahuan mahasiswa Universitas Sumatera Utara 2010 tentang asupan makanan berserat terhadap kelancaran buang air besar (skripsi). Medan: Fakultas Kedokteran Universitas Sumatera Utara; 2010.

10. Sugondo S. Obesitas. Dalam: IImu Penyakit Dalam Jilid III. Edisi ke-4. Jakarta: Pusat Penerbitan Departemen IImu Penyakit Dalam Universitas Indonesia; 2006. hlm.1919-24. 